\title{
ENDURANCE TIME IN SLOW AND FAST CONTRACTING MUSCLE GROUPS
}

\author{
by Svend Molbech, M.Sc. and Sophus H. Johansen, M.D.*
}

Molbech, S. and Johansen, S. H. Work-environm.-hlth 10 (1973) 62-64. Endurance time in slow and fast contracting muscle groups. The endurance time (the maximum duration of a sustained isometric muscle contraction) of a slow and fast contracting muscle group was investigated in six subjects. The muscle groups examined were the plantar and the dorsal flexors of the ankle joint. The measurements were made with a $90^{\circ}$ flexion in the knee joint. After determination of the maximum isometric muscle strength, the endurance time was measured at 50 per cent of the maximum strength. The plantar flexors showed a statistically significant longer endurance time than did the dorsal flexors. This indicates that the ability of a muscle group to maintain a sustained isometric contraction depends on the relative proportion of slow and fast contracting muscle fibers.

Striated muscles are composed of slow and fast contracting muscle fibers $(2,3)$. The slow (red) fibers are ich in mitochondria and myoglobin and are relatively in, whereas fast (white) fibers contain a smaller number of mitochondria, less myoglobin, have a larger diameter, and are richer in glycogen. Schmalbruck (7) analyzed human muscles for fiber types and demonstrated that the soleus muscle contained $89 \%$ slow fibers (type $C$ ), whereas the tibial muscle contained $46 \%$ only, the rest being composed of B and A fibers, which are poorer in mitochondria.

Rohmert (6) demonstrated that endurance time (the maximum duration of a sustained isometric muscle contraction) was independent of muscle group and subject and only dependent on the relative load.

In an earlier study (5) we found that endurance time in elbow flexion during partial curarization was significantly decreased with + tubocurarine but showed a tendency to increase with decamethonium. The slow and fast fibers have a different sensitivity towards curarizing agents. The marked reduction in endurance time found with + tubocurarine thus was explained by the facts that the slow fibers are best fit for sustained isometric contraction, and at the same time more sensitive towards the drug than the fast fibers.

The Danish National Association for Infantile Paralysis, and the Department of Anesthesia II, Gentofte Hospital, Hellerup, Denmark.
These results suggest that endurance time, defined as the maximum time an isometric muscle contraction can be maintained at a constant tension, could vary with the content of slow and fast fibers.

The aim of this study, therefore, was to investigate whether there is a difference in the endurance times of two muscle groups, which are known to be slow and fast, respectively. For this purpose we have chosen to study m.soleus in a plantar flexion under conditions which reduce the contribution of the gastrocnemius muscle to a minimum, and m.tibialis anterior in dorsal flexion of the ankle joint.

Table 1. Subjects' data, the mean values of three measurements on each subject of the maximum isometric strength in plantar and dorsal flexion, and the corresponding average endurance times at approx. $50 \%$ of the maximum isometric strength.

\section{Methods and Procedures}

The subjects were placed in the supine position on a table with $90^{\circ}$ flexion in the hip and knee joints, the thigh being fastened to a vertical board, the lower leg fastened on a horizontal plate. The subjects wore solid shoes on which a modified ice skate was screwed and strapped in the conventional position so that the forces exerted were transmitted from the tip of the skate. A strain gauge dynamometer was mounted on a wire which connected the tip of the skate with either a complete fixation - for the maximum isometric strength measurements - or a trundle, $15 \mathrm{~cm}$ diameter, on ball bearings for the endurance time measurements.

\begin{tabular}{|c|c|c|c|c|c|c|c|c|}
\hline \multirow[t]{2}{*}{ Subj. } & \multirow[t]{2}{*}{ Sex } & \multirow[t]{2}{*}{$\begin{array}{c}\text { Age } \\
\text { years }\end{array}$} & \multirow[t]{2}{*}{$\underset{\mathrm{cm}}{\text { Height }}$} & \multirow[t]{2}{*}{$\begin{array}{l}\text { Weight } \\
\mathbf{k g}\end{array}$} & \multicolumn{2}{|c|}{$\begin{array}{l}\text { Maximum isometric } \\
\text { strength }\end{array}$} & \\
\hline & & & & & $\begin{array}{l}\text { plantar } \\
\text { flexion }\end{array}$ & $\begin{array}{l}\text { dorsal } \\
\text { flexion }\end{array}$ & $\begin{array}{l}\text { plantar } \\
\text { flexion }\end{array}$ & $\begin{array}{l}\text { dorsal } \\
\text { flexion }\end{array}$ \\
\hline $\begin{array}{l}\mathrm{KH} \\
\mathrm{BO} \\
\mathrm{AJ}\end{array}$ & $\frac{q}{-}$ & $\begin{array}{l}44 \\
30 \\
17\end{array}$ & $\begin{array}{l}162,5 \\
176,0 \\
166,0\end{array}$ & $\begin{array}{l}65,5 \\
64,5 \\
55,0\end{array}$ & $\begin{array}{r}80,7 \\
98,9 \\
73,0 \\
\end{array}$ & $\begin{array}{l}25,6 \\
34,3 \\
34,7\end{array}$ & $\begin{array}{l}2,75 \\
3,86 \\
4,16\end{array}$ & $\begin{array}{l}1,63 \\
1,25 \\
1,60\end{array}$ \\
\hline $\begin{array}{l}\text { BS } \\
\text { LJ } \\
\text { AP }\end{array}$ & $\frac{0}{-}$ & $\begin{array}{l}56 \\
19 \\
18\end{array}$ & $\begin{array}{l}166,5 \\
182,0 \\
179,0\end{array}$ & $\begin{array}{l}73,0 \\
76,0 \\
68,0\end{array}$ & $\begin{array}{r}69,9 \\
103,0 \\
106,0\end{array}$ & $\begin{array}{l}33,0 \\
39,2 \\
34,0\end{array}$ & $\begin{array}{l}3,71 \\
3,29 \\
3,48\end{array}$ & $\begin{array}{l}1,98 \\
1,17 \\
1,88\end{array}$ \\
\hline $\begin{array}{l}\text { Overall average } \\
\text { S.D. }\end{array}$ & & & & & & & $\begin{array}{r}3,54 \\
\pm 0,56\end{array}$ & $\begin{array}{r}1,58 \\
\pm 0,34\end{array}$ \\
\hline
\end{tabular}


All measurements were performed on the same leg, with the ankle joint at $90^{\circ}$. The tensions were recorded by means of an ink writing potentiometer.

The experiments were performed on each subject with several days' intermission. After strapping the subject to the test table three maximum isometric flexions were performed with intervals of a few seconds. The best of the three was taken as the maximum isometric strength for that test day. The subject then rested for $20 \mathrm{~min}$. In the meantime a load corresponding to $50 \%$ of the maximum strength was attached to the skate via the wire and hung over the trundle. After the resting period, the subject was told to hold this load with the ankle at $90^{\circ}$ as long as possible. The maximum time the foot could be kept in the right position was the endurance time. Endurance time was investigated in three female and three male subjects ranging from 17 to 56 years of age.

\section{Results}

The characteristics of the subjects appear in table 1 , as do the values of maximum plantar and dorsal flexion (average of the three best results, one for each test day). It also shows the average of the corresponding endurance times measured at approx. $50 \%$ of the maximum isometric strength $(50,0 \% \pm 0,5$ for plantar flexion, and $50,0 \% \pm 0,7$ for dorsal flexion). The strength in plantar flexion is two to three times greater than in dorsal flexion. The difference in endurance time between plantar and dorsal flexion at the same relative load ( $50 \%$ of $\max$. strength) is statistically significant ( $p<0,005$, Student's $t$ test, paired observations).

\section{Discussion}

The observed difference in endurance time between the two muscle groups cannot be explained by differences in blood flow. Hydrostatic factors will diminish blood flow to the same degree in both muscles in the experimental position, and it is most likely that circulation through the muscles is severely impeded at an isometric contraction of $50 \%$ of the maximum strength $(1,4)$.

At the onset of static work in a sub-maximal contraction producing $50 \%$ of the maximum isometric strength, the degree of effort will be moderate. As time passes, the effort will increase, and at the cessation of the endurance time period the effort will be maximum, although the mechanical tension is unchanged. The distribution of the tension-producing fibers will change during the work period, as fatigue gradually affects more and more fibers. The fibers poorest in myoglobin are the first to be affected during static (isometric) work of such long duration that anaerobic processes become predominant.

The number of capillaries per muscle fiber in red muscle, and thus the larger oxygen store, cannot explain the observed difference in endurance time. ( $p<0,005$, Student's $t$ test, paired observations). ( $<<0,005$, Student's $t$ test, paired observations).

In isometric plantar flexion the prime muscle will be soleus, especially when the lower extremity is flexed in the knee joint; this flexion minimizes the contribution of tension from the gastrocnemius muscle. In dorsal flexion the most important muscle will be the anterior tibial muscle. Due to the difference in distribution of fiber types in the two muscles, soleus will be better fit for static work than tibialis; this explains the difference in endurance time between the two muscle groups found at $50 \%$ of the maximum isometric strength. The difference could actually be explained by any decisive difference in the physiological functions, characteristic of the two fiber types. The most obvious explanation, however, seems to be the relatively long duration of the single contraction of the slow, red muscle fiber. In a submaximum contraction, tetanus is achieved at a lower frequency than in a fast, white fiber. Thus a given mechanical tension can be produced by a relatively smaller number of fibers. The endurance time of the dorsal flexors is in good agreement with Rohmert's data (6), whereas that found for plantar flexion is significantly longer.

This means that the composition of muscles, as regards the distribution of fiber types, will influence the tension-time curve in such a way that predominana of slow $\mathrm{C}$ fibers will prolong endurance time, at least at $50 \%$ of the maximum isometric strength.

The finding seems to indicate the importance of choosing mainly muscle groups with a relatively high content of red muscle fibers for occupational work dominated by isometric (static) work and for work of long duration with more or less impeded circulation. Also the finding might explain differences in fatigue in different muscle groups during occupational work. As endurance time seems dependent not only on the relative load put on the muscle during static contraction, but also on the muscle composition, the maximum isometric strength of a muscle group does not give a true picture of the capability to perform static work. When training muscle strength (e.g., patients during and after hospitalization, rehabilitees after a period of unemployment) it is likely that the type of training used infiuences the maximum isometric strength and the endurance time of the same muscle group to different extents depending on the tendency of the training to increase red properties of the involved muscle fibers.

\section{References}

'Barcroft, H. and Millen, J. L. E. The blood floy) through muscle during sustained contraction. J. physiol., (Lond.) 97 (1939) 17-31.

${ }^{2}$ Guth, L. Trophic influences of nerve on muscle. Physiol. rev. 48 (1968) 645-687.

s Hess, A. Vertebrate slow muscle fibers. Physiol. rev. 50 (1970) $40-62$.

- Humphreys, $P$. W. and Lind, A. R. The blood flow through active and inactive muscles of the forearm during sustained handgrip contractions. J. Physiol., (Lond.) 166 (1963) 120-135.

'Molbech, S. and Johansen, S. H. Endurance time in static work during partial curarization. J. appl. physiol. 27 (1969) 44-48.

- Rohmert, $W$. Ermittlung von Erholungspausen für statische Arbeit des Menschen. Int. Z. angew. Physiol. 18 (1960) 123-164.

${ }^{7}$ Schmalbruck, $H$. Die quergestreifen Muskelfasern des Menschen. Ergebn . Anat. Entwickl.-Gesch. 43 (1970) $1-73$. 